\title{
Experiencias de las personas trans en el ámbito de la atención primaria
}

\author{
Trans individuals'experiences in primary care
}

\section{Comentado de:}

Bell J, et al. Can Fam Physician. 2019 65(4):e147-e154. PMID: $30979772^{1}$

\section{Objetivos}

Explorar las experiencias y describir las expectativas de los miembros de la comunidad trans respecto a la atención otorgada por sus médicos/as de familia.

\section{Diseño}

Investigación cualitativa con enfoque fenomenológico llevada a cabo en Kingston, Ontario (Canadá) durante 2016.

\section{Participantes}

Mediante un muestreo por conveniencia, el estudio incluyó a 11 individuos mayores de 18 años que se auto perciben como trans, reclutados a través de agencias comunitarias y clínicas de medicina familiar.

\section{Métodos}

Entrevistas semiestructuradas g rabadas y transcriptas verbalmente, realizadas por los investigadores sobre la base de seis tópicos que habían surgido de los aportes de líderes locales de la comunidad trans: 1) el uso de servicios de atención primaria de la salud; 2) las necesidades de salud específicas de las personas trans; 3) su relación con quienes trabajan en el ámbito de la medicina familiar; 4) las experiencias con profesionales en formación; 5) el ambiente clínico; 6) las formas de mejorar la calidad de la atención.

Dos investigadores realizaron en forma independiente un análisis temático de las transcripciones, usando para el procesamiento de datos el programa Nvivo. La información fue presentada través de un resumen de cada tema recurrente y de una tabla, donde fueron expuestas citas textuales de las respuestas de los/as participantes.

\section{Hallazgos principales}

Cuatro personas fueron identificadas como hombres trans, seis como mujeres trans y una de ellas, como de género no binario.

Los investigadores formularon significados a partir de frases comunes que surgieron en las entrevistas y organizaron la información recolectada en cinco temas recurrentes: el conocimiento médico sobre las identidades trans, la auto agenciación en el sistema de salud, la discriminación, los espacios positivos y las expectativas sobre el cuidado ideal.

Las personas trans esperan que su médico de familia les otorgue un entorno adecuado para la evaluación y/o las prescripciones hormonales, y para la derivación para recibir cirugías de afirmación de género.

\section{Conclusiones}

La comunidad trans tiene muchas necesidades de salud física y mental que no están siendo atendidas por el actual sistema de salud. Quienes trabajan en el ámbito de la medicina familiar necesitan capacitarse y ganar confianza para iniciar terapias de hormonización, así como para instrumentar derivaciones vinculadas con cirugías de afirmación de género. Aunque otros especialistas pueden tener un papel importante para algunos pacientes, la mayoría de las personas trans tiene la expectativa de contar con un profesional que cumpla el rol de médico/a de familia, recibiendo de este/a los cuidados principales.

\section{Comentario}

El desarrollo de un estudio cualitativo basado en el enfoque fenomenológico implica el relevamiento de la percepción del grupo en estudio, añadiendo además su participación en el proceso metodológico. Esto permite acercarnos a las voces que pretendemos conocer y que los lectores también formemos parte del proceso llevado a cabo por los investigadores, lo que contribuye a que pongamos en marcha nuestros posicionamientos y valores personales durante la resignificación de lo que leemos.

Por otro lado, el objetivo de un trabajo de investigación cualitativo con enfoque fenomenológico nunca tiende a que sus resultados/conclusiones puedan generalizarse y abarcar a una mayoría poblacional. Más aún, este trabajo está orientado hacia una cosmovisión transformadora que enfatiza la examinación de asuntos relacionados con las relaciones de poder, la justicia social y la opresión de individuos que se encuentran fuera de la masa poblacional generalizable, por diversas situaciones dependientes del contexto.

Es así que rescatar la importancia de que el proceso investigativo haya sido colaborativo, pondera las expectativas de los participantes y ayuda a generar posiciones más sólidas para mejorar la organización de los cuidados de salud de las personas trans, que como grupo social precarizado tiene urgentes necesidades de revisión de sus problemáticas sociosanitarias. Desde que la Ley de Identidad de Género fue promulgada y aceptada en 2012 en Argentina ${ }^{2}$, tanto los profesionales de la salud que nos desempeñamos en el ámbito de la atención primaria como los diversos especialistas, hemos tenido nuevas directivas en cuanto a lo que implica la atención de personas cuyo género no se percibe de la misma manera que el asignado al nacer. Entre esas directivas se contemplan las garantías a aquellos derechos fundamentales que se habían visto obstaculizados hasta ese entonces, porque les obligaba a las personas trans a atravesar por un sistema que no tenía aún pautas claras sobre qué hacer con dichas demandas, ni cómo hacerlo. Considerando este avance en materia de derechos humanos como un puntapié inicial para ir dejando atrás la desinformación y el estigma como barreras que dificultan el acceso sanitario, celebramos las investigaciones que nos ayudan a conocer y entender las percepciones y expectativas de las personas trans sobre esta relativamente nueva incorporación de sus vivencias dentro de los sistemas sanitarios. 


\section{Conclusiones de la comentadora}

Los profesionales que nos desempeñamos en el ámbito de la atención primaria tenemos un rol imprescindible en el acercamiento de los grupos minoritarios al sistema de salud y que las personas trans prefieren que formemos parte de su cuidado integral, dejando un claro mensaje de la necesidad de capacitación y mayor compromiso de los/a médicos/as de familia para asumir esta tarea.

Agustina Vega [ Servicio de Medicina Familiar y Comunitaria, Hospital Italiano de Buenos Aires, Argentina. agustina.vega@hospitalitaliano.org.ar ]

Vega A. Experiencias de las personas trans en el ámbito de la atención primaria . Evid Actual Pract Ambul. 2020;23(1):e002043. Comentado de: Bell J, et al. Trans individuals ' experiences in primary care. Can Fam Physician. 2019 Apr;65(4):e147-e154. PMID: 30979772

\section{Referencias}

1. Bell J, Purkey E. Trans individuals' experiences in primary care. Can Fam Physician. 2019;65(4):e147-e154.

2. Ciudad Autónoma de Buenos Aires, Argentina Ministerio de Justicia y Derechos Humanos, Secretaría de Derechos Humanos . Ley № 26.743. Identidad de género.; 2014. Available from: http://www.jus.gob.ar/media/3108867/ley_26743_identidad_de_genero.pdf [Last access: 2020-01-20]. 